\title{
Viljasadon korjuu ja varastointi
}

Hannu Haapala, Timo Lötjönen, Hannu Mikkola, Jani Aho, Henrik Sarin, Tapani Kivinen ja Tuija Alakomi

Maa- ja elintarviketalouden tutkimuskeskus, maatalousteknologian tutkimus, Vakolantie 55, 03400 VIHTI, etunimi.sukunimi@mtt.fi

\section{Johdanto}

Viljan tuottajahinta on Suomessa laskenut puoleen tai jopa neljänteen osaan siitä, mitä se oli ennen Suomen liittymistä Euroopan Unioniin. Tuottajien tulonmenetyksiä on kompensoitu tuilla, mutta myös kustannuksia pitäisi karsia tuotantoa tehostamalla. Ennen Agenda-ratkaisua viljasta saatu hinta riitti parhailla tiloilla peittämään viljelyn muuttuvat kustannukset, mutta Agendan jälkeen tukea on käytettävä myös muuttuvien kustannusten kattamiseen, vertaa Ala-Mantila \& Riepponen 1998.

Viljasadon korjuu ja kuivaus ovat viljelyketjun kalleimmat yksittäiset vaiheet. Aaltonen et al. (1999) ovat laskeneet, että vuonna 1997 keskimääräinen puintikustannus oli 12,4 p/kg ja kuivauskustannus $21,0 \mathrm{p} / \mathrm{kg}$. Jollei kustannuksia onnistuta alentamaan, viljanviljely nykymuodossaan on taloudellisesti kannattamatonta tuetkin huomioon ottaen. Lyhyestä korjuukaudesta johtuen kapasiteettia tarvitaan paljon ja sen käyttöaika on lyhyt. Siksi kiinteiden kustannusten merkitys on keskeinen (Klemola \& Pirilä 1999). Esimerkiksi puintikustannuksesta niiden osuus oli Aaltosen et al. (1999) mukaan $62 \%$ ja kuivauskustannuksesta $71 \%$. Tutkimuksen tavoitteeksi asetettiinkin selvittää, voidaanko viljan korjuu- ja varastointikustannuksia alentaa $25 \%$ :lla eli keskimäärin 10 pennillä kiloa kohden kymmenen vuoden kuluessa (vrt. Aaltonen et al. 1999).

Tuotannon laajentaminen on nähty ehkä tärkeimpänä keinona alentaa kiinteitä kustannuksia. Osa tiloista lopettaa tuotannon ja jatkaville tarjoutuu mahdollisuus laajentaa vuokraamalla tai ostamalla lisää peltoa. Tilojen verkottuminen ja yhteistoiminta olisi ratkaisu, jolla pienemmätkin tilat voisivat hyödyntää uutta tehokasta kalustoa ja alentaa kiinteitä kustannuksiaan. Näin taattaisiin riittävän ja ammattitaitoisen työvoimareservin säilyminen maatalouden piirissä. Työvoimaa on vaikeaa saada sesonkiluonteisiin töihin ja ammattitaidottoman tilapäistyövoiman käyttö kiireisessä sadonkorjuussa johtaa helposti taloudellisiin vahinkoihin ja työtapaturmien lisääntymiseen. Nykytekniikka on osin niin kehittynyttä, että ammattitaidoton henkilö ei suoriudu sen käytöstä.

Yli puolet viljasadosta käytetään rehuna ja huomattava osa tästä viljasta voitaisiin säilöä tuoresäilöntämenetelmiä käyttäen. Tuoresäilöntä on houkutteleva vaihtoehto, koska viljaa voidaan korjata heti keltatuleentumisesta lähtien ja huonommalla säällä kuin kuivattavaksi aiottua viljaa. Leikkuupuimuria voidaan tällöin käyttää pitemmällä jaksolla ja tuoresäilönnän vastaanottokapasiteetti saadaan vastaamaan puintikapasiteettia ilman suuria kustannuksia. Viljan viljely ja säilöminen tuoreena rehuksi saattaisi olla jopa kilpailukykyinen vaihtoehto leipäviljan tuottamiselle, koska rehuviljan ja muuhun käyttöön menevän viljan hintaero on selvästi supistunut siitä, mitä se oli ennen EU:iin liittymistä.

Viljan hinnan laskun ja tuen suuren osuuden vuoksi satovaihteluilla ja huonosta säästä johtuvilla korjuutappioilla ei ole enää niin suurta merkitystä kuin ennen. Siksi korjuukapasiteettia ei ehkä kannata mitoittaa pahimman vaan enintään keskimääräisen sään mukaan. Lisäkapasiteetin osto vuokraamalla voi olla edullisempaa kuin oman hankkiminen ja pelkästään omaan käyttöön tulevien koneiden hankkimista kannattaa harkita entistä tarkempaan. Koneiden taloudellinen käyttöikä suhteessa niiden luotettavuuteen ja huoltokustannuksiin on sovitettava vallitsevien talouden raamien mukaan.

\section{Aineisto ja menetelmät}

Tutkimusta varten nähtiin tarpeelliseksi luoda matemaattinen malli, jonka avulla voidaan monipuolisesti simuloida erilaisia vaihtoehtoja sekä tuotantotekijöissä tapahtuvien muutosten vaikutuksia. Malli perustuu olemassa olevaan kirjallisuustietoon, jota on tarpeen mukaan jalostettu käyttöön soveltuvaksi. Kolmantena tutkimusmenetelmänä mallintamisen ja kirjallisuustiedon ohella haluttiin käyttää koerakentamista suunnittelusta valmiiseen rakennukseen asti.

Viljan korjuu mallinnettiin viljan kypsymishetkestä varastointiin saakka. Malli on dynaaminen ja sillä voidaan simuloida korjuukustannus millä tahansa korjuukauden hetkellä tai minä tahansa vuonna ottaen sääolot huomioon. Aiemmin viljasadon korjuuta ja varastointia on kuvattu lähinnä osamalleilla, jotka pystyvät yleensä vain staattisen tilan kuvaamiseen.

Korjuukustannusten laskennassa malli käytti prosenttipoistomenetelmää ja käytetyt poistoajat olivat pitkiä (esim. traktorit 12 vuotta, puimuri 15 vuotta, kuivuri 25 vuotta). Tavanomaisten työ-, 
kone- ja rakennuskustannusten lisäksi malli otti huomioon ajallisuuskustannuksen, jonka suuruuteen vaikuttavat käytettävissä oleva kapasiteetti ja sää. Mallin validoinnissa käytetyt menetelmät olivat datavalidointi, hypoteesivalidointi, tekninen validointi sekä kokonaisvalidointi (Gustafsson et al. 1982). Mallin laskemia tuloksia verrattiin koti- ja ulkomaisessa alan kirjallisuudessa esitettyihin tuloksiin (mm. Sörensen 1996, Klemola \& Pirilä 1999). Malli tarjoaa mahdollisuuden simuloida rajattoman määrän eri muuttujien yhdistelmiä, mutta tutkimusta varten yhdistelmät rajattiin neljään tilakokoon, joille valittiin kapasiteetiltaan järkevä koneistus. Tilat olivat siis kuvitteellisia, mutta kuitenkin kasvivalikoiman, koneistuksen ja työvoiman osalta sellaisia, että lähes vastaavia tiloja Suomesta varmasti löytyy.

Koerakentamiskohteina oli yksi lämminilmakuivuri ja yksi monikäyttöinen kylmäilmakuivuri. Kuivurit suunniteltiin yhteistyössä viljelijöiden kanssa. Kylmäilmakuivuri myös rakennettiin tutkimuksen aikana ja sillä ehdittiin kuivata ensimmäiset erät.

\section{Tulokset ja tulosten tarkastelu}

Korjuu ja varastointi -tietokonemalli

Mallin avulla voidaan monipuolisesti tutkia korjuuketjun pullonkaulatöitä, työn ja kapasiteetin tarvetta sekä kustannuksia. Seuraamalla simuloinnin kulkua voidaan omin silmin havainnollisesti nähdä, miten sadejakson aikana korjuu viivästyy ja ajallisuuskustannus kasvaa tai miten työmäärä ruuhkaantuu poutajakson aikana. Käytetyn mallinnusohjelmiston etuna on syy-seuraussuhteiden graafinen esitystapa ja dynaamisten tapahtumien mallinnusmahdollisuus. Esimerkiksi konerikon, tapaturman tai vaihtelevan sään vaikutus on helppo simuloida. Korjuuketjun herkkyys muuttujien arvojen muutoksille saadaan mallin avulla selville. Mallintaminen paljastaa myös tiedon aukkokohtia ja epätarkkuuksia. Esimerkiksi korkean vesipitoisuuden vaikutus puimurin puintitehoon tunnetaan huonosti. Ulkomaisten puimurivalmistajien suositus sopivasta viljan puintikosteudesta yleensä loppuu siihen, mistä sen pitäisi Suomessa alkaa. Viljojen ränsistymistä, varisemista ja laadun kestävyyttä korjuun viivästyessä on myös tutkittu liian vähän.

Malli on varsin käyttökelpoinen tutkijakäytössä, mutta neuvoja- tai viljelijäversion aikaansaaminen vaatisi lisätyötä. Malli soveltuisi tuotannon suunnittelun apuvälineeksi, mutta mallia käytettäessä tarvitaan tehokas tietokone, mallinnusohjelma ja käyttäjän on hallittava ohjelma sekä tunnettava mallin rakenne. Suunnittelukäytössä mallin sisältämät hintatiedot pitäisi päivittää säännöllisesti.

Korjuu- ja varastointikustannusten alentaminen

Viljan korjuu tulee erittäin kalliiksi pienillä, noin 30 hehtaarin tiloilla, jos käytetään omaa uudehkoa puimuria ja kuivuria. Puinnin ja kuivauksen teettäminen vuokratyönä alentaisi kustannusta 30 - 35 p/kg. Suurempien 70, 120 ja 200 hehtaarin tilojen korjuukustannukset ovat vain noin puolet 30 hehtaarin tilan kustannuksista, eikä tilakoko enää 70 hehtaarin jälkeen juurikaan alenna korjuukustannusta. Järkevästi mitoitettujen koneiden kapasiteetti saadaan käytettyä 70, 120 ja 200 hehtaarin tiloilla lähes täysimääräisesti hyväksi. Keskikokoisilla ja suurilla tiloilla tasapainoillaan ajallisuuskustannuksen ja työ- ja konekustannusten välillä. Vuokrapuimurin käyttö todettiin kannattavaksi aina 120 hehtaarin alaan saakka.

Puinnin jälkeisten käsittely- ja varastointimenetelmien (lämminilmakuivaus, kylmäilmakuivaus, murskesäilöntä, jyväsäilöntä) kustannuserot olivat 120 hehtaarin tilalla yllättävän pieniä, $1-3 \mathrm{p} / \mathrm{kg}$. Tämä johtuu siitä, että mallissa tuoresäilöntää varten on ajateltu hankittavan kunnon varastosiilot. Monestihan maatiloilla tuoresäilöttyä viljaa voidaan varastoida muusta käytöstä poistetuissa varastoissa (esimerkiksi vanhat laakasiilot). Ilmatiivis säilöntä oli $10 \mathrm{p} / \mathrm{kg}$ muita menetelmiä halvempaa. Laskelmassa oletettiin, että ilmatiivis siilo rakennetaan käytetyistä elementeistä, joiden hinta $60-77 \%$ uusien elementtien hinnoista. Suuri, käytetyistä elementeistä rakennettu siilo on kaikkein edullisin.

Puskurikuivurin rakentaminen lisäämään vanhan kuivurin kapasiteettia voi olla kannattavaa. Samoin viljasadon säilöminen osittain propionihapolla, jos vaihtoehtona on kokonaan uuden kuivurin rakentaminen. Kun uusi lämminilmakuivuri päätetään rakentaa, siitä kannattaa kuitenkin tehdä niin tehokas, että sen kapasiteetti riittää yksinään. Kylmäilmakuivaus kannattaa pienillä tiloilla, mutta ei suurilla. Jyvä- ja murskesäilöntä on likimain yhtä kallista kuin lämminilmakuivaus, jos samalla ei hyödynnetä tehokkaan vuokrapuimurin käyttöä ja mahdollisuutta korjata viljaa myös tuleentumattomana. Rehuviljaa tuottavilla tiloilla on paljon paremmat mahdollisuudet saavuttaa tavoiteltu $25 \%$ :n kustannussäästö kuin leipä- ja siemenviljaa tai mallasohraa tuottavilla tiloilla. Ajallisuuskustannuksen merkitys on vähentynyt, mutta mallin mukaan korjuukustannus oli kosteana syksynä 1998 jopa 15 p/kg suurempi kuin kuivana syksynä 1997. Ero johtui ensisijaisesti juuri ajallisuuskustannuksesta. 
Korjuu- ja varastointikustannusten herkkyys Korjuu- ja varastointikustannusten herkkyys tarkoittaa sitä, miten paljon kustannus muuttuu, kun lähtöarvoja muutetaan tietty määrä. Kuvassa 1 on esitetty tilanne 120 hehtaarin tilalla vuoden 1998 korjuuoloissa. Nollakohdaksi on valittu kustannus $(53 \mathrm{p} / \mathrm{kg})$, joka on saavutettu lämminilmakuivausmenetelmää käyttäen. Muuttujien arvoja on pienennetty tai suurennettu yksi kerrallaan $10 \%$, ja kuvasta nähdään, mitä muutos vaikuttaa korjuu- ja varastointikustannukseen. Osa muuttujista vaikuttaa kustannukseen symmetrisesti, mutta esimerkiksi viljan puintikosteuden lisääntyminen lisää kustannuksia vähemmän kuin kosteuden alentuminen kustannuksia alentaa. Tämä johtuu siitä, että energiaa ja aikaa tarvitaan kuivaamiseen sitä enemmän, mitä lähempänä varastointikosteutta ollaan.

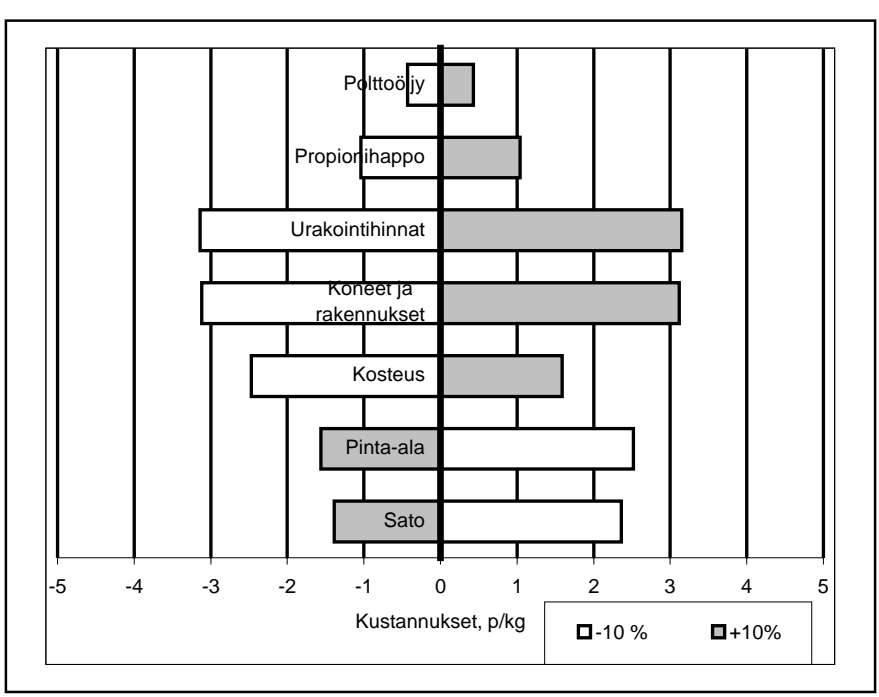

Kuva 1. Korjuu- ja varastointikustannuksen herkkyys eräille mallin muuttujien arvojen muutoksille. Nollakohta kuvaa 120 hehtaarin viljatilan korjuukustannusta, kun vilja kuivataan lämminilmakuivurissa tai säilötään hapolla (propionihappovaihtoehto) (Haapala et. al. 2001).

\section{Koerakentaminen}

Tutkimuksen aikana suunniteltiin koerakennuskohteina ajonkestävä, monikäyttöinen kylmäilmakuivuri sekä lämminilmakuivuri. Kylmäilmakuivuri myös rakennettiin ja rakennushanke on raportoitu Vakolan rakennusratkaisuja sarjassa numerolla 8/2000. Suunnittelun tärkein tavoite oli monikäyttöisyys. Kuivurissa oli voitava kuivata viljan lisäksi haketta, sipulia ja heinää. Kylmäilmakuivurin rakentaminen sujui suunnitelmien mukaan ja kustannusarvio $\left(2360 \mathrm{mk} / \mathrm{m}^{2}\right)$ hieman alitettiin. Ensimmäiset käyttökokemukset ovat osoittaneet kuivurin vastaavan viljelijän odotuksia. Lämminilmakuivuri suunniteltiin valmiiksi, mutta hanke ei edennyt rakentamisvaiheeseen asti. Viljelijä katsoi investoinnin liian suureksi investointituesta huolimatta.

\section{Johtopäätökset}

Vain alentamalla kiinteitä kustannuksia voidaan oleellisesti alentaa korjuu- ja varastointikustannusta, koska kiinteiden kustannusten osuus kaikista kustannuksista on 2/3. Rehuviljaa tuottavilla tiloilla on enemmän ja parempia mahdollisuuksia tuotantokustannusten alentamiseen kuin leipäviljaa, mallasohraa tai siemenviljaa tuottavilla tiloilla. Tuoresäilöntä ja korjuu tehokkaalla vuokrapuimurilla ovat yhdistelmä, jolla tavoiteltu $25 \%$ :n kustannussäästö on useimmiten saavutettavissa. Suomen viljasadosta käytetään rehuksi yli $60 \%$, mutta siitä huolimatta $90 \%$ sadosta puidaan ja kuivataan kuten leipävilja.

Urakoitsijan käyttö puintiin tai kuivaukseen tai molempiin alentaa korjuukustannuksia aina 120 hehtaariin saakka. Pienillä tiloilla urakoitsijan käyttö voi alentaa kustannuksia jopa $50 \%$. Rehuviljan korjuukautta voidaan pitkittää lajikevalinnalla helpommin kuin myöhään tuleentuvien leipäviljojen. Tällöin selvitään pienemmällä kapasiteetilla ja pienemmillä kiinteillä kustannuksilla, jos käytetään omaa kalustoa. Korjuukauden pitkittäminen parantaa myös mahdollisuuksia saada urakoitsija ajallaan töihin. Oman puimurin ja kuivurin käyttö muutaman kymmenen hehtaarin viljatilalla on järkevää vain, jos koneet voidaan hankkia murto-osalla uusien hinnasta ja ne voidaan pitää käyttökunnossa omin voimin halvoilla purkuosilla.

Leipäviljan tai mallasohran viljelijöiden näkökulmasta riittävän suuri hintaporras rehuviljaan verrattuna motivoi parhaiten pitämään yllä kapasiteettia, jolla korkealaatuinen sato saadaan korjattua ajallaan. Liian korkea hintaporras puolestaan houkuttelee useimpia viljantuottajia pyrkimään leipä- ja mallaslaatuun ja kustannukset karkaavat jälleen käsistä. Oikea portaan korkeus löytynee vain seuraamalla säännöllisesti kauppaan tulevan viljan laatua ja määrää sekä tutkimalla viljelijöiden halukkuutta investoida korjuukalustoon.

Kustannusten alentaminen ei saa huonontaa kotimaisen viljan laatua, koska Suomessa ei voida kilpailla määrällä. Tuoresäilötty vilja on todettu hyväksi rehuksi niin märehtijöille, sioille kuin ka- 
noillekin. Kun vilja säilötään huolellisesti, kustannuksia ei karsita eläinten tai eläintuotteiden laadun kustannuksella. Kustannusten rankka karsiminen kotimaisen leipäviljan ja mallasohran korjuu- ja varastointikustannuksista huonontaa melko varmasti laatua ja huonontaa toimitusvarmuutta. Pienen ajallisuuskustannuksen houkuttelemana viljelyalaa lisätään, mutta puinti- ja kuivauskapasiteetti pidetään ennallaan. Hyvinä korjuukausina omavaraisuus saavutetaan ja huonoina vuosina laatuvaatimukset täyttävää viljaa on tuotava. Näin on jouduttu tekemään ennenkin, mutta tiukan kustannusjahdin seurauksena tuontivuosia olisi nykyistä useammin.

\section{Kirjallisuus}

Aaltonen, J., Järvenpää, M., Klemola, E. \& Laurila, P. 1999. Viljan korjuu-, kuivaus- ja logistiikkakustannukset Suomessa. Maatalouden taloudellinen tutkimuslaitos, selvityksiä 2/99. 22 s. ISSN 1239-4548

Alakomi, T., Kivinen, T., Mikkola, H. \& Sarin, H. 2000. Ajonkestävä monikäyttöinen kylmäilmakuivuri. Maatalouden tutkimuskeskus, Vakolan rakenneratkaisuja 8/2000. 16 p. ISSN 1237-2099

Ala-Mantila, O. \& Riepponen, L. 1998. Maatalouden tuotantokustannukset Suomessa. Maatalouden taloudellinen tutkimuslaitos, tutkimuksia 222. $120 \mathrm{~s}$. . ISSN 1239-8799

Gustafsson, L., Lanshammar, H. \& Sandblad B. 1982. System och modell. En introduktion till systemanalysen. Lund, Studentlitteratur. 275 p. ISBN 91-44-18551-0

Haapala, H., Lötjönen, T., Mikkola, H., Aho, J., Sarin H., Kivinen, T. \& Alakomi, T. 2001. Viljasadon korjuu ja varastointi. Maatalouden tutkimuskeskus, Vakolan tutkimusselostus 78. 63 p. ISSN 0782-0054

Klemola, E. \& Pirilä, J. 1999. Viljankorjuun kustannukset Suomessa. Työtehoseuran maataloustiedote 8/1999 (512). Vihti. 6 p. ISSN 0782-6788

Sörensen, C. 1996. Höst af korn, baelgsaed, frö og raps. Driftsteknisk analyse. Forskningsrapport nr. 49. Landbrugs- og Fiskeriministeriet. Statens Husdyrbrugsforsög. Frederiksberg. 92 p. ISSN 0908-021X 